\section{Treatment adequacy for anxiety and depressive disorders in six European countries}

\author{
A. FERNÁNDEZ, J. M. HARO, M. MARTINEZ-ALONSO, K. DEMYTTENAERE, \\ T. S. BRUGHA, J. AUTONELL, G. DE GIROLAMO, S. BERNERT, J. P. LÉPINE \\ and J. ALONSO
}

\begin{abstract}
Summary The aims of this study are to describe the adequacy of treatment for anxiety and depressive disorders in Europe and how it differs between providers, using data from the ESEMeD study. The overall proportion of adequate treatment was $45.8 \%$ ( $57.4 \%$ in the specialised sector and $23.3 \%$ in the general medical care sector). Betweencountry differences were found in treatment adequacy in the specialised setting. Organisational and political aspects may explain these findings.
\end{abstract}

\section{Declaration of interest Partial \\ funding from several drug companies involved in the manufacture of antidepressant medication; full acknowledgements in a data supplement to the online version of this paper.}

Research on quality of care for mental disorders has systematically reported low rates of treatment guideline adherence (Ramana et al, 1999; McConnell et al, 2002; Oquendo et al, 2002; Kessler et al, 2003; Wang et al, 2005). This has significant health consequences, since treatments meeting clinical guidelines are cost-effective and decrease years lived with disability (Andrews et al, 2004). The majority of previous studies have been conducted in the USA, and little is known about treatment adequacy in Europe.

This study is based on a European epidemiological study of the prevalence and treatment of mental disorders. Our aims are to describe treatment adequacy for anxiety and depressive disorders in Europe, how it differs between countries and providers, and which factors are associated with appropriate care.

\section{METHOD}

The European Study of the Epidemiology of Mental Disorders (ESEMeD) project is a cross-sectional household survey representative of the non-institutionalised adults of Belgium, France, Germany, Italy, The Netherlands and Spain. A stratified, multistage, clustered area, probability sample without replacement design was used. Data for the project were provided by 21425 respondents. A description of the ESEMeD methodology has been provided by Alonso et al (2004). Response rates ranged from $45.9 \%$ in France to $78.6 \%$ in Spain.

Mental health status was assessed with the Composite International Diagnostic Interview 3.0 (Kessler \& Ustun, 2004). The diagnoses included in this paper were DSMIV major depressive episode and anxiety disorders (social phobia, generalised anxiety disorder and panic disorder) (American Psychiatric Association, 1994). Individuals reporting any use of health services as a result of their 'emotions or mental health problems' in the 12 months before the interview were asked to select whom they visited from a list including psychiatrist, psychologist, general practitioner (GP) or any other medical doctor. Psychiatrists and psychologists constituted the specialised mental health category; GPs and other doctors formed the general medical care category.

Criteria for minimally adequate treatment were receiving antidepressant pharmacotherapy (for depression) or antidepressant or anxiolytic pharmacotherapy (for anxiety) for at least 2 months plus at least four visits with a psychiatrist, a GP or any other doctor; or at least eight sessions with a psychologist or a psychiatrist lasting an average of $30 \mathrm{~min}$ (American Psychiatric Association, 1998, 2000; Guidelines Advisory Committee, 2001; Kessler et al, 2003; Royal Australian and New Zealand College of Psychiatrists, 2003; National Institute for Clinical Excellence, 2004; Wang et al, 2005).

Data were weighted to adjust for the multistage probability sampling. Population projection weights were used to restore the representativeness of the sample regarding age and gender distribution in each country. A logistic model was used to analyse factors associated with treatment adequacy. Since the same individual could have received treatment in both the specialised and general medical sectors, a generalised estimating equation model was used, including two observations for those treated in both sectors (Zeger \& Liang, 1986). Statistical analyses were carried out using Stata version 8.0 and SAS veresion 9.1 for Windows.

\section{RESULTS}

An average of $29.5 \%$ (429 individuals) of those with a diagnosis of major depressive episode or anxiety disorder in the past 12 months had consulted any health service during that period. Of these individuals, 59 lived in Belgium, 89 in France, 49 in Germany, 36 in Italy, 62 in The Netherlands and 134 in Spain. The overall proportion of treatment adequacy for any disorder was $45.8 \%$ (95\% CI 39.2-52.4), ranging between $45.8 \%$ (95\% CI 38.47-53.05) for major depressive episode and $54.5 \%$ (95\% CI 44.7864.19) for anxiety disorder. By setting, rate of treatment adequacy for any disorder was $57.4 \%$ (95\% CI 49.7-65.1) in the specialised care category and $23.3 \%$ (95\% CI $16.7-$ $29.8)$ in the general medical care category (specialised care as reference, $\mathrm{OR}=0.25$, 95\% CI 0.16-0.38). The same pattern was observed for both types of disorder.

By country, overall proportions of adequacy varied from $32.5 \%(95 \%$ CI $21.5-43.2)$ in Spain to $55.4 \%(95 \%$ CI $40.3-70.5)$ in The Netherlands $(P=0.11)$. The proportion of individuals receiving minimally adequate treatment in the specialised care varied widely, from $29.2 \%(95 \%$ CI $17.4-41.0)$ in Spain to $78.2 \%$ (95\% CI 65.4-91.0) in France $(P<0.001)$. In the general medical setting, proportions varied between $14.9 \%(95 \%$ CI 1.0-28.7) in Belgium and 33.6\% (95\% CI 14.4-52.9) in Italy $(P=0.54)$.

Being treated by a general medical provider was associated with a lower probability of receiving adequate treatment in Belgium $(\mathrm{OR}=0.24$, 95\% CI 0.19-0.64), France $(\mathrm{OR}=0.09,95 \%$ CI $0.04-0.23)$, Germany $(\mathrm{OR}=0.16$, 95\% CI $0.05-0.56)$ and The Netherlands $(\mathrm{OR}=0.35,95 \% \mathrm{CI}$ 0.18-0.69). Provider differences in each country according to disorder were similar to the overall differences.

Two different models were run in order to ascertain the factors associated to treatment adequacy. After adjusting by gender, age (centralised around median value, 42 years 
old), urbanicity (living in a city with $>100,000$ inhabitants $v$. smaller), presence or absence of chronic illness, and health state assessed using the EuroQol, only type of provider and country were related to treatment adequacy. As some interaction between provider and country was detected, we adjusted a second model. In this model, provider by itself was not significant (taking specialised care as reference, $\mathrm{OR}=0.76,95 \% \mathrm{CI} 0.34$ 1.71). Using Spain as reference, living in France $(\mathrm{OR}=8.91,95 \%$ CI 3.37-23.55), Germany $(\mathrm{OR}=5.16$, 95\% CI 1.81-14.18) and The Netherlands $(\mathrm{OR}=5.14,95 \% \mathrm{CI}$ 1.94-13.62) was related to increased probability of receiving adequate treatment. Only the interactions between provider (generalised care) and France $(\mathrm{OR}=0.10,95 \% \mathrm{CI}$ $0.03-0.35)$ or Germany ( $\mathrm{OR}=0.20,95 \%$ CI 0.05-0.84) were statistically significant. (The results are summarised in a data supplement to the online version of this paper.)

\section{DISCUSSION}

Results should be interpreted considering the following limitations. First, information about treatment was self-reported. Second, the final sample considered was small and data should be interpreted with caution. Third, we have not been able to analyse how national differences in response rate affect the results. Finally, we might have underestimated treatment inadequacy owing to the loose criteria used .

In spite of the limitations, our results suggest that treatment adequacy rates for anxiety disorders and major depressive episodes in Belgium, France, Germany, Italy, The Netherlands, and Spain are similar to those found by Wang et al (2005) in the USA. Rates of minimal adequate treatment in the USA were $52.0 \%$ in the specialised setting and $14.9 \%$ in the general medical setting; in Europe the rates were $57.4 \%$ and $23 \%$ respectively. However, Wang's study included all DSM-IV diagnoses, whereas we focused on only two types of disorder.

Although overall rates of adequacy were similar across Europe, the differences between providers varied. In the northern countries (Belgium, France, Germany and The Netherlands) treatment adequacy was higher in the specialised sector, whereas in the southern countries (Italy and Spain) there was no difference. This result was not anticipated, since published studies systematically report that those treated in a specialised setting are more likely to receive adequate treatment (Knieser et al, 2005; Wang et al, 2005).

A. FERNÁNDEZ, Paediatrics, Obstetrics and Gynaecology, and Preventive Medicine Department, Universitat Autònoma de Barcelona, Spain, J. M. HARO, Research and Development Unit, Sant Joan de Déu Mental Health Services, Fundació Sant Joan de Déu, Barcelona. Spain; M. MARTINEZ-ALONSO, Health Services Research Unit, Institut Municipal d'Investigació Mèdica (IMIM), Barcelona, Spain, K. DEMYTTENAERE, University Hospital Gasthuisberg, Leuven, Belgium; T. S. BRUGHA, University of Leicester, Leicester, UK; J. AUTONELL, Research and Development Unit, Sant Joan de Déu Mental Health Services, Fundació Sant Joan de Déu, Barcelona, Spain; G. DE GIROLAMO, Azienda USL Città de Bologna, Italy; S. BERNERT, University of Leipzig, Leipzig, Germany; J. P. LÉPINE, Hôpital Fernand Widal, Paris, France; J. ALONSO, Health Services Research Unit, Institut Municipal d'Investigació Medica and Universitat Autònoma de Barcelona, Barcelona. Spain

Correspondence: Anna Fernández, Research and Development Unit, Sant Joan de Déu Mental Health Services, Carrer del Doctor Pujades, 4208830 Sant Boi de Llobregat, Barcelona, Spain. Tel: + 3493640 6350 ext.2373; email: afernandez@sjd-ssm.com

(First received 20 February 2006, final revision 26 July 2006, accepted I September 2006)

Differences in European healthcare systems might explain these variations. Spain and Italy have a national health service financed by general taxation; the other countries have a system of compulsory social health insurance. In Spain and Italy a GP referral is usually needed to access specialised care. Practice guidelines could also explain differences. Practice guidelines have, at least theoretically, an important role in France, Germany and The Netherlands. In France, the National Agency for Accreditation and Evaluation of Health Care has published a depression guideline; Germany has an Institute for Quality and Efficiency that promotes evidence-based treatments; and in The Netherlands both GPs and psychiatrists publish guidelines for depression (more information on the healthcare systems of these countries can be obtained from the European Observatory, http://www.euro.who.int/observatory). However, the role of practice guidelines has been questioned by Gilbody et al (2003), who highlight the point that simple guideline creation is ineffective. The finding that France and Germany have a high overall adequacy rate but low adequacy in the general medical setting, whereas The Netherlands has one of the highest rates of treatment adequacy in the general medical setting, could be explained by the fact that guidelines in The Netherlands were developed by both primary care physicians and specialists, supporting the hypothesis that collaborative care improves quality of care.

\section{REFERENCES}

Alonso, J., Angermeyer, M. C., Bernert, S., et al (2004) Sampling and methods of the European Study of the Epidemiology of Mental Disorders (ESEMeD) project. Acta Psychiatrica Scandinavica Supplement, 420, 8-20.

American Psychiatric Association (1994) Diagnostic and Statistical Manual of Mental Disorders (4th edn) (DSM-IV). APA.

American Psychiatric Association (1998) Practice Guidelines for Treatment of Patients with Panic Disorder. APA
American Psychiatric Association (2000) Practice Guideline for Treatment of Patients with Major Depressive Disorder. APA.

Andrews, G., Issakidis, C., Sanderson, K., et al (2004) Utilising survey data to inform public policy: comparison of the cost-effectiveness of treatment of ten mental disorders. British Journal of Psychiatry, 184, 526-533.

Gilbody, S., Whitty, P., Grimshaw, J., et al (2003)

Educational and organizational interventions to improve the management of depression in primary care. JAMA, 289, 3145-3151.

Guidelines Advisory Committee (200I)

Outpatient Management of Depression. CAG. http: / / www.gacguidelines.ca

Kessler, R. C., Berglund, P., Demler, O., et al (2003) The epidemiology of major depressive disorder: results from the National Comorbidity Survey Replication (NCS-R). JAMA, 289, 3095-3105.

Kessler, R. C. \& Ustun, T. B. (2004) The World Mental Health (WMH) Survey Initiative version of the World Health Organization (WHO) Composite International Diagnostic Interview (CIDI). International journal of Methods in Psychiatry Research, 13, 93-121.

Knieser, T. J., Powers, R. H. \& Croghan, T.W. (2005) Provider type and depression treatment adequacy. Health Policy, 72, 321-332.

McConnell, P., Bebbington, P., McClelland, R., et al (2002) Prevalence of psychiatric disorder and the need for psychiatric care in Northern Ireland: population study in the District of Derry. British Journal of Psychiatry, I8I, 214-219.

National Institute for Clinical Excellence (2004) Management of Depression in Primary and Secondary Care. NICE. http: / / www. nice.org.uk

Oquendo, M. A., Kamali, M., Ellis, S. P., et al (2002) Adequacy of antidepressant treatment after discharge and the occurrence of suicidal acts in major depression: a prospective study. American Journal of Psychiatry, I59, 1746-1751.

Ramana, R., Paykel, E. S., Surtees, P. G., et al (1999) Medication received by patients with depression following the acute episode: adequacy and relation to outcome. British Journal of Psychiatry, 174, 128-134.

Royal Australian and New Zealand College of Psychiatrists (2003) Australian and New Zealand clinical guidelines for the treatment of panic disorder and agoraphobia, Australian and New Zealand Journal of Psychiatry, 37, 641-656.

Wang, P. S., Lane, M., Olfson, M., et al (2005) Twelve month use of mental health services in the US: Results from the National Comorbidity Survey Replication (NCS-R). Archives of General Psychiatry, 62, 629-640.

Zeger, S. L. \& Liang, K. Y. (1986) Longitudinal data analysis for discrete and continuous outcomes. Biometrics, 42, I21-30. 